\title{
O movimento operário no interior paulista: uma análise das greves gerais de 1917 e 1919 em Piracicaba
}

\author{
The labour movement in the countryside of São Paulo: an analysis \\ of the general strikes of 1917 and 1919 in Piracicaba
}

\section{Fabiana Ribeiro de Andrade Junqueira*}

Resumo: A segunda década do século XX foi marcada por duas grandes greves gerais de operários, respectivamente nos anos 1917 e 1919. Os trabalhadores da cidade de São Paulo exerceram papel importante na história do movimento proletário desse período e foram os primeiros a cruzarem os braços na busca por profundas reformas sociais que melhorassem ou mesmo transformassem radicalmente as condições de vida da classe trabalhadora do país, influenciando militantes e operários em diferentes municípios do interior do estado e até mesmo em outras unidades federativas do Brasil. As paralisações, no entanto, ganharam contornos próprios em cada uma das cidades tomadas pela classe trabalhadora. As greves operárias de 1917 e 1919 em Piracicaba mantiveram semelhanças com os movimentos paredistas da capital paulista, mas também foram marcadas por peculiaridades que podem nos ajudar a compreender a complexa atuação dos trabalhadores nas pequenas e médias cidades brasileiras durante a Primeira República. Este artigo pretende, portanto, analisar esses dois importantes eventos no município, comparando-os com as mobilizações verificadas na capital, apontando as conexões e as singularidades regionais.

Palavras-chave: Greves operárias de 1917 e 1919; Piracicaba; Primeira República.

Abstract: The second decade of the twentieth century was marked by two major general worker strikes, respectively in the years 1917 and 1919. Workers in the city of São Paulo played an important role in the history of the proletarian movement of that period and were the

Doutoranda em História Social pela Universidade Estadual de Campinas (Unicamp). Graduada e Mestre em História pela Universidade Federal de São Paulo (UNIFESP). ORCID: https://orcid.org/0000-0003-3431-6188. E-mail: fabijunqueira8@gmail.com. 
first to cross their arms in the search for profound social reforms that would improve or even radically transform the living conditions of the country's working class; influencing militants and workers in different municipalities in the interior of the state and even in other federal units in Brazil. The stoppages, however, took on specific shapes in each of the cities taken by the working class. The 1917 and 1919 workers' strikes in Piracicaba maintained similarities with the wall movements of the São Paulo capital, but they were also marked by peculiarities that may help us to understand the complex performance of workers in small and medium-sized Brazilian cities during the First Republic. This article intends to analyze these two important events in the municipality, comparing them with the mobilizations verified in the capital, pointing out the regional connections and singularities.

Keywords: Workers' strikes; Piracicaba; Brazil Republic.

\section{Introdução}

A GREVE GERAL DE 1917 teve início no dia 8 do mês de junho na fábrica de tecidos Cotonifício Rodolfo Crespi em São Paulo. Iniciada por mulheres, a greve rapidamente ganhou a adesão dos outros operários do cotonifício, depois de outras fábricas da capital, de outros ramos, e terminou alcançando outras cidades e estados. Diferentes regiões do Brasil tiveram seus estabelecimentos industriais completamente paralisados; entre as cidades que aderiram a esse grande movimento paredista constam: Campinas, Jundiaí, Limeira, Santos, São Roque, Sorocaba, Belo Horizonte, Pelotas, Porto Alegre, Recife e Rio de Janeiro. ${ }^{1}$ Foi a maior greve do período e ficou imortalizada na memória do movimento proletário. Em 1919, novos levantes operários ocorreram em diferentes unidades da federação, e em algumas cidades, como em Piracicaba, transformaram-se em greves gerais. Algumas das bandeiras levantadas pela classe trabalhadora em todo o país em 1919 permaneceram as mesmas de 1917, como a tão almejada jornada de 8 horas de trabalho conquistada naquele momento apenas por algumas categorias operárias. $^{2}$

As mobilizações de 1917 e 1919 inspiraram um razoável número de trabalhos acadêmicos e cada vez mais os historiadores do trabalho têm se esforçado em demonstrar que, embora haja conexões entre o movimento da capital paulista e os de outros estados, havendo inclusive uma pauta comum de reivindicações, as greves das demais cidades do país não foram meros reflexos do movimento original de 1917 em São Paulo. ${ }^{3}$ O movimento

1 BIONDI, Luigi; TOLEDO Edilene. Uma revolta urbana: a greve geral de 1917 em São Paulo. São Paulo: Fundação Perseu Abramo, 2018.

2 Uma análise comparada das greves gerais operárias de 1917 e 1919 nas cidades de Salvador, Recife, Porto Alegre, Rio de Janeiro e São Paulo foi realizada por Aldrin Castellucci em: CASTELLUCCI, Aldrin. Guerra, revolução e movimento operário: as greves gerais de 1917-1919 no Brasil em perspectiva comparada. In: SPERANZA, Clarice Gontarski (org). História do trabalho: entre debates, caminhos e encruzilhadas. Jundiaí: Paco Editorial, 2019.

3 Ver: CASTELLUCCI, Aldrin. Flutuações econômicas, crise política e greve geral na Bahia da Primeira 
operário de cada uma das unidades federativas do Brasil possui semelhanças, mas também peculiaridades, e não podem ser reduzidas a um efeito colateral da região Sudeste. A partir dessa premissa, alguns pesquisadores se debruçaram sobre os contornos dessas greves nos demais estados brasileiros. Atualmente é possível encontrar trabalhos publicados sobre os movimentos paredistas de 1917 ou 1919 em cidades como Recife, Salvador, Porto Alegre e Rio de Janeiro. ${ }^{4}$ Entretanto, ainda são raras as análises dedicadas às pequenas e médias cidades do território nacional; a historiografia centrada nos grandes centros urbanos não abordou as particularidades econômicas, sociais e políticas dos municípios interioranos.

A dimensão que tomou o movimento paredista em São Paulo contribuiu para ofuscar a leitura centralizada nos diferentes municípios do estado paulista, que muitas vezes foram compreendidos apenas à luz dos eventos da capital. ${ }^{5} \mathrm{~A}$ leitura atenta da imprensa sugere que essa interpretação também foi promovida pelos jornalistas durante as greves de 1917 e 1919 . Em Piracicaba, os principais periódicos noticiaram o advento das greves no município a partir da relação com os eventos em São Paulo. Assim, em 1917, o Jornal de Piracicaba publicou:

A greve dos operários na capital, embora terminada, não podia deixar de repercutir no interior do Estado.

Anteontem, à noite, foi distribuído pela cidade um boletim concitando os operários de Piracicaba a cruzarem os braços, deixando de comparecer ao trabalho como um signal de solidariedade aos seus companheiros da capital. ${ }^{6}$

A Gazeta de Piracicaba, outro importante periódico do município, seguiu o mesmo movimento do Jornal de Piracicaba nessa greve e publicou:

A agitação operária, a primeiro momento limitada à capital paulista, ameaça alastrar-se pelo interior do Estado, tomando um caráter alarmante. ${ }^{7}$

Em 1919, um movimento paredista em Piracicaba se iniciou após a paralisação dos trabalhadores ferroviários em toda a linha da Estrada de Ferro Sorocabana. A greve começou com os operários da Sorocabana em São Paulo e o Jornal de Piracicaba afirma:

Segundo comunicação que recebemos ontem de São Paulo, o movimento paredista vem se alastrando na Sorocabana. ${ }^{8}$

Os operários das indústrias piracicabanas deflagram um movimento paredista em 1919, após a greve na ferrovia que também passava por Piracicaba. Novamente a greve se inicia entre os ferroviários da capital e a mobilização operária no município é compreendida como um

República. Revista Brasileira de História, São Paulo, v. 25, n. 50, 2005.

4 CASTELLUCCI, op. cit.

5 Christina Roquette Lopreato abordou sucintamente a greve operária de 1917 em algumas cidades do interior paulista, como Campinas e Sorocaba, em sua tese de doutorado defendida no Departamento de História da Unicamp em 1996, posteriormente publicada em livro. Ver: LOPREATO, Christina Roquette. O espírito da revolta. A greve geral anarquista de 1917. São Paulo: Annablume, 2000

6 Jornal de Piracicaba, Piracicaba, 17 jul. 1917. Grifos da autora. Biblioteca Municipal de Piracicaba, Piracicaba, SP.

7 Gazeta de Piracicaba, Piracicaba, 15 jul. 1917. Grifos da autora. Biblioteca Municipal de Piracicaba, Piracicaba, SP.

8 Jornal de Piracicaba, Piracicaba, 1 jul. 1919. Grifos da autora. Biblioteca Municipal de Piracicaba, Piracicaba, SP. 
resultado direto dos eventos da metrópole..$^{9} \mathrm{O}$ uso dos termos "alastrar" e "repercutir" ou a explicação dada pelo Jornal de Piracicaba de que a greve geral de 1917 seria um movimento de solidariedade aos operários da capital, reforçam a relação direta entre o município e São Paulo. Neste artigo, pretendo apresentar as várias conexões entre o movimento paredista que ocorreu em Piracicaba e aqueles vividos em São Paulo nos conturbados anos da Primeira República, mas também almejo deixar uma singela contribuição aos historiadores e observar as peculiaridades do movimento paredista operário em Piracicaba. A história e a historiografia do trabalho poderão atingir um outro patamar analítico a partir da articulação das pesquisas regionais, ou seja, do cruzamento das informações sobre a vida e o movimento da classe proletária nas várias pequenas, médias e grandes cidades brasileiras.

\section{Piracicaba e a classe obreira durante a Primeira República}

AO NOS DEBRUÇARMOS sobre os trabalhos acadêmicos centrados na história do estado de São Paulo durante a Primeira República, é comum o destaque dado pelos historiadores à produção cafeeira e todas as implicações sociais, políticas e econômicas geradas por essa cultura no Brasil. O café impulsionou vigorosamente o desenvolvimento financeiro de todo o estado de São Paulo, fomentando a construção das ferrovias paulistas para o escoamento da produção e financiando a imigração estrangeira que serviu como mão de obra nos cafezais, transformando São Paulo em um importante centro político do país. Todavia, os municípios paulistas não vivenciaram o grande ciclo cafeeiro de maneira idêntica. Na cidade de Piracicaba, por exemplo, o café dividiu sempre o espaço com a plantação canavieira. A história de Piracicaba é marcada por uma atividade econômica presente na história do Brasil desde o período colonial: a produção do açúcar.

Piracicaba foi fundada no ano de 1767, margeada pelo rio que inspirou a famosa canção Rio de Lágrimas, da década de 1970. Para os memorialistas da cidade, a terra roxa às margens do rio Piracicaba, dentre vários outros aspectos naturais, propiciou que a cidade compusesse no século XVIII o que se convencionou chamar de "Quadrilátero do Açúcar", região formada por importantes núcleos produtores de açúcar como Sorocaba, Mogi-Guaçu e Jundiaí. Diferentes pesquisadores do município citam o fato de em 1816 constar na solicitação oficial de elevação da freguesia de Piracicaba à condição de vila (o que só ocorreu em 1822), o argumento de que em Piracicaba já haveria 14 engenhos de açúcar e 4 de água ardente, e que, em 1836, a cidade já possuía 78 engenhos. A plantação canavieira e os engenhos de açúcar marcam profundamente o cenário do município da sua fundação até os nossos dias. ${ }^{10}$

9 Jornal de Piracicaba, Piracicaba, 5 jul. 1919. Biblioteca Municipal de Piracicaba, Piracicaba, SP.

10 NEME, Mário. História da fundação de Piracicaba. Piracicaba: Editora João Mendes da Fonseca, 1943. PETRONE, Thereza Sherer. A lavoura canavieira em São Paulo. São Paulo: Difusão Europeia do Livro, 1968. CANABRAVA, Alice e TEIXEIRA, Mendes M. A região de Piracicaba. Revista do Arquivo Municipal, São Paulo, v. 4, n. 45, p. 275-338,1938. 
Diferentemente do que ocorreu em outras cidades do interior paulista, como Campinas, onde a plantação cafeeira foi avançando progressivamente, em Piracicaba, durante o século XIX e primeiras décadas do século XX, ela se estabilizou, e a cana-de-açúcar, artigo que sempre foi importante na cidade, foi novamente tomando espaço nas fazendas. ${ }^{11} \mathrm{Na}$ cidade de Piracicaba, foi comum, durante todo o ciclo cafeeiro paulista, as duas culturas - cana e café - coexistirem em uma mesma propriedade, inclusive nas terras dos engenhos. A retomada da expansão canavieira tornou-se possível sobretudo através do processo de modernização do setor açucareiro com a instalação de dois engenhos centrais, o Engenho Central de Piracicaba, fundado em 1881, e o Engenho Central de Monte Alegre, fundado em $1887 .{ }^{12}$

O Engenho Central de Piracicaba é hoje um importante ponto turístico e espaço cultural da cidade; um patrimônio tombado pelo Condepac (1989) e pelo Condephaat (2014), tamanha foi a marca desse estabelecimento na história da cidade. Existem ainda vestígios materiais da Usina Monte Alegre e todo o bairro no qual a usina está localizada é um importante patrimônio histórico do município. ${ }^{13}$ Ao longo do século XIX e primeiras duas décadas do século XX, foram espaços de conflitos entre os trabalhadores e seus patrões.

A pesquisadora Eliana Tadeu Terci, em sua tese de doutorado defendida na Universidade de São Paulo em 1997, dedicou parte de um capítulo às greves operárias em Piracicaba durante os anos 1889 até 1930; esse é um dos poucos trabalhos acadêmicos que abordam as greves gerais de 1917 e 1919 no município. ${ }^{14} \mathrm{O}$ estudo da autora destaca alguns conflitos entre os colonos e o gerente do Engenho Central antes da deflagração da primeira greve geral em 1917. ${ }^{15}$ No interior do engenho, os colonos eram responsáveis por plantar e posteriormente vender a cana-de-açúcar ao estabelecimento, não eram detentores da propriedade em que produziam e assinavam contratos de prioridade com a Société de Sucreries Brésiliennes, proprietária do engenho desde 1899. No momento da venda, foram verificadas várias tensões entre os colonos e o gerente do engenho, geralmente porque exigia-se dos colonos valor muito abaixo do mercado. ${ }^{16}$ Alguns desses embates resultaram em greves no interior do estabelecimento que foram noticiadas nos jornais do período. Em 1902, a Gazeta de Piracicaba publicava:

11 RAMOS, Pedro. História Econômica de Piracicaba (1765-1930): as particularidades do complexo canavieiro paulista. In: TERCI, Eliana Tadeu (org). O desenvolvimento de Piracicaba. História e perspectivas. Piracicaba: Editora UNIMEP, 2001.

12 BILAC, Maria Beatriz Bianchini, TERCI, Eliana Tadeu, PADILHA, Danieli Alves, MAESTRELLO, Ana Paula Vedovato. Piracicaba, a aventura desenvolvimentista (1950-1970). Piracicaba: UNIMEP, 2001.

13 PERES, Maria Thereza Miguel Peres. O colono de cana na modernização da Usina Monte Alegre: Piracicaba (1930-1950). Dissertação (Mestrado) - Programa de Estudos Pós-Graduados, Pontifícia Universidade Católica de São Paulo, São Paulo, 1990.

14 TERCI, Eliana Tadeu. A cidade na Primeira República: imprensa, política e poder em Piracicaba. Tese (Doutorado) - Faculdade de Filosofia, Letras e Ciências Humanas, Universidade de São Paulo, São Paulo, 1997.

15 Sobre Piracicaba na Primeira República, consultar: PACANO. F. A. O forjar da modernidade: Piracicaba e a belle époque caipira (1989-1930). Tese (Doutorado) - Instituto de Geociências e Ciências Exatas do Campus de Rio Claro, Universidade Estadual Paulista Júlio de Mesquita Filho, UNESP, Rio Claro, 2018.

16 TERCI, 1997, op. cit. 
ainda uma vez, anteontem, estiveram em greve os colonos do Engenho Central da Companhia Sucrèrie de Piracicaba. Motivou-a o quererem aqueles que se elevasse o preço dos carros de cana, de 12 para $15 \$ 000$, e a isso não ceder o gerente daquele estabelecimento. Ao que nos disse este, não o podia fazer, nem a isso tinham direito os colonos em face do contrato escrito existente entre a Companhia e os mesmos. Com quem estava a razão, enfim não o sabemos. É uma questão de direito que só como tal poderá ser resolvida. ${ }^{17}$

Embora, como lembra Terci, os conflitos rurais não fossem uma exclusividade de Piracicaba, matérias como essa apresentada pela autora nos conduzem ao cenário obreiro da cidade durante a Primeira República. No interior dos principais estabelecimentos fabris do município, no caso, os engenhos centrais, que a essa época eram verdadeiras usinas de açúcar, trabalhavam operários no setor de maquinamento, como mecânicos, caldeireiros e fundidores, ao lado dos colonos da cana, responsáveis pela lavoura. Foram esses os trabalhadores que participaram das primeiras greves gerais no município e deram início às mobilizações da classe trabalhadora na cidade. A existência de tensões no Engenho Central de Piracicaba também sugere que o advento das greves de 1917 e 1919 não foram movimentos espontâneos, frutos unicamente de uma conjuntura específica desses anos. As greves gerais na cidade não ocorreram apenas como um sinal de solidariedade aos operários da capital, como defendeu o Jornal de Piracicaba durante o movimento, mas foram resultados de uma história de insatisfação e de uma série de conflitos que já vinham ocorrendo no interior de cada um dos estabelecimentos da cidade.

Além do café e da cana-de-açúcar, a cidade também produziu o algodão que experimentou um breve ciclo de prosperidade durante as décadas de 1860 e 1870. Nessa mesma época, precisamente em 1873, foi instalada uma importante fábrica de tecidos no município. O empreendimento que inicialmente se chamava Santa Francisca (1873), depois Arethusina (1902) e finalmente Fábrica Boyes, foi fundado por Luiz Vicente de Sousa Queiroz, o mesmo idealizador da Escola Agrícola de Piracicaba (1901), que hoje, denominada Escola Superior de Agricultura Luiz de Queiroz/ESALQ, é um campus pertencente à Universidade de São Paulo/USP. ${ }^{18}$

A fábrica foi posta em funcionamento no ano 1876 e começou a operar com 70 trabalhadores que produziam cerca de 600 a 700 mil metros de algodão por ano. Essa unidade produtiva funcionou durante grande parte do século $\mathrm{XX}$ e passou por vários proprietários até decretar falência. ${ }^{19}$ Hoje, seus vestígios materiais são tombados pelo município. Embora não haja atualmente ações efetivas que garantam sua preservação, além das várias pressões

17 Gazeta de Piracicaba, Piracicaba, 24 jul. 1902 apud: TERCI, Eliana Tadeu. A cidade na Primeira República: imprensa, política e poder em Piracicaba. Tese (Doutorado) - Faculdade de Filosofia, Letras e Ciências Humanas, Universidade de São Paulo, São Paulo, 1997.

18 GUERRINI, L. História de Piracicaba em quadrinhos. Piracicaba: Instituto Histórico e Geográfico de Piracicaba, 1970.

19 PERECIN, Marly Therezinha Germano. A síntese urbana (1822-1930). Piracicaba: Equilíbrio; Instituto Histórico e Geográfico de Piracicaba, 1989. 
imobiliárias, a fábrica Arethusina durante a Primeira República se destacou como um dos maiores estabelecimentos industriais no cenário nacional. Para Eduardo Ferraz:

Pela sua magnitude, a Arethusina fugia dos padrões industriais da Primeira República, cuja marca eram as pequenas empresas, de mínima capitalização e base técnica artesanal. Para o ano de 1919, as indústrias de 200 a 499 empregados, dentre as quais a fábrica piracicabana se inclui, representavam apenas $1,1 \%$ do total em São Paulo e $1,8 \%$ no Rio de Janeiro. ${ }^{20}$

Ao lado da Arethusina também compunha o cenário industrial de Piracicaba outro grande estabelecimento: a Casa Krähenbühl. Fundada em 1870 por Pedro Krähenbühl, possuía 40 operários e produzia trolleys e tílburis. Entre o final do século XIX e início do XX, a família Krähenbühl, de origem suíça, instalou uma carpintaria, uma serraria e uma oficina mecânica que, além da fundição do bronze, fabricava fogões e arados. O Almanaque de Piracicaba do ano de 1955 aponta a Casa Krähenbühl como pioneira do setor no estado de São Paulo. ${ }^{21} \mathrm{~A}$ fábrica completou 100 anos em maio de 1970, ocasião em que foi publicada uma reportagem sobre sua trajetória no jornal O Estado de São Paulo. No entanto, do início do século XX restaram poucos vestígios, havendo apenas algumas fontes iconográficas e algumas referências em periódicos locais e estaduais. ${ }^{22}$

O Engenho Central de Piracicaba, o Engenho Monte Alegre, a fábrica de tecidos Arethusina e a Casa Krähenbühl eram os maiores e mais importantes estabelecimentos fabris do município durante as greves gerais de 1917 e 1919. Foram os trabalhadores desses locais que concitaram o movimento grevista na cidade e, ao mesmo tempo, foram esses os estabelecimentos que ganharam destaque no Jornal de Piracicaba durante o desenrolar do movimento paredista. Todavia, ao lado desses grandes empreendimentos fabris, funcionava uma série de outros pequenos comércios, fabriquetas e oficinas, cujos proprietários tiveram que negociar com a classe trabalhadora a fim de conseguirem o encerramento do movimento grevista e voltarem à normalidade. Entre elas podemos citar: Braga \& Cia, Casa di Lascio, Polacow e Irmão, Casa Nova York, Paschoal Gerriri \& Irmãos, Pedro Botenne \& Filhos e Serraria Aliança. ${ }^{23}$

Até os anos 1930, Piracicaba não sofreu muitas alterações no cenário rural ou industrial, mantendo-se como uma importante cidade produtora de açúcar, marcada pela plantação canavieira, pela produção em menor escala de alguns outros cereais como milho, e cítricos como a laranja, e por alguns grandes e outros pequenos estabelecimentos fabris. Ao longo dos primeiros 30 anos do século $\mathrm{XX}$, o café foi decrescendo no município até atingir a crise de 1929 e perder definitivamente importância. ${ }^{24}$ A produção do açúcar, ao contrário, foi se

20 FERRAZ, Eduardo L. L. Acidentados e remediados: a lei de acidentes no trabalho na Piracicaba da Primeira República (1919-1930). Revista Mundos do Trabalho, Florianópolis, v. 2, n. 3, p. 206-235, 2010.

21 KRÄHENBÜHL, Hélio. Almanaque de Piracicaba - 1955. Piracicaba: João Mendes Fonseca, 1955.

22 O Estado de São Paulo, 3 maio 1970. Arquivo Público do Estado de São Paulo.

23 Jornal de Piracicaba, 19 jul. 1917. Biblioteca Municipal de Piracicaba, Piracicaba, SP.

24 BILAC, Maria Beatriz Bianchini, TERCI, Eliana Tadeu. Piracicaba: de centro policultor a centro canavieiro, 1930-1950. Núcleo de Pesquisa e Documentação Regional, FAP/PIBIC-CNPq. Piracicaba: MB Editora, 2001. 
expandindo, principalmente após a criação do Instituto do Açúcar e do Álcool (IAA) em 1933, que através de uma série de medidas beneficiou Piracicaba e contribuiu para que a cidade fosse a maior produtora dessa mercadoria em todo o estado de São Paulo até 1960, quando perdeu seu posto para Sertãozinho, município localizado na região metropolitana de Ribeirão Preto. ${ }^{25}$

A partir da Segunda Guerra Mundial (1939-1945), a cidade experimentou um vertiginoso crescimento do setor metalúrgico com a expansão da fábrica Dedini, fundada em 1920. Seu fundador, Mário Dedini, um imigrante italiano, comprou o setor mecânico da Krähenbühl na década de 1940, e a empresa, ativa até hoje, se tornou a maior metalúrgica do município e uma grande companhia nacional no pós-guerra. ${ }^{26} \mathrm{Na}$ cidade de Piracicaba aconteceu uma conjugação do setor metalomecânico com a produção sucroalcooleira, uma vez que o Grupo Dedini produzia equipamento de usinagem, chegando mesmo a construir usinas completas para a fabricação do álcool e do açúcar. ${ }^{27} \mathrm{~A}$ partir da década de 1950, os metalúrgicos passam a se destacar na liderança do movimento operário piracicabano, ao lado dos trabalhadores no setor da alimentação, que inclui os operários das grandes usinas presentes até hoje na região. Ainda hoje, os trabalhadores nas indústrias mecânicas, metalúrgicas e de material elétrico formam uma das maiores e mais organizadas categorias da cidade, que conta com outras fábricas como a Caterpillar, instalada na década de 1970, e a Hyundai, inaugurada já no século XXI. ${ }^{28}$

\section{O desenvolvimento dos movimentos grevistas em Piracicaba}

1917

A GREVE GeRAL DE 1917 em São Paulo terminou oficialmente no dia 16 de julho. Entretanto, alguns historiadores já demonstraram que muitos empresários se recusaram a assinar o acordo apresentado pelo Comitê de Defesa Proletária e preferiram negociar diretamente com seus empregados; tal fato fez com que os trabalhadores fossem voltando pouco a pouco às fábricas paulistanas. ${ }^{29}$ Enquanto o movimento paredista, que tomou ares de uma verdadeira revolta urbana na capital, caminhava para o fim, em Piracicaba a classe trabalhadora se reunia com o objetivo de iniciar o que viria a ser a maior mobilização obreira verificada no município até aquela época.

25 SAMPAIO, Silvia Selingardi. Geografia industrial de Piracicaba: um exemplo de interação indústria-agricultura. Tese (Doutorado) - Faculdade de Filosofia, Ciências e Letras de Rio Claro, Universidade Estadual Paulista Júlio de Mesquita Filho, Rio Claro, 1973.

26 NEGRI, Barjas. Estudo de caso da indústria nacional de equipamentos-análise do Grupo Dedini (19201970). Instituto Histórico e Geográfico de Piracicaba - IHGP. Piracicaba: Editora Equilíbrio, 2010.

27 SAMPAIO, op. cit.

28 JUNQUEIRA, Fabiana R. de A. Trabalhadores do aço na terra da cana: os metalúrgicos e a formação da classe operária em Piracicaba (1945-1968). In: 30 Simpósio Nacional de História - ANPUH, Recife/PE. Anais [...]. Recife: UFPE, 15 a 19 de julho de 2019. Disponível em: https://www.snh2019.anpuh.org/site/anais\#F. BIONDI; TOLEDO, op. cit. 
Era domingo, dia 15 de julho, quando alguns trabalhadores distribuíram de mãos em mãos nas ruas e nas portas das oficinas e engenhos de Piracicaba um panfleto no qual convocavam os companheiros a decretarem greve geral. Na segunda-feira pela manhã, novo boletim foi distribuído na cidade, dessa vez convidando os piracicabanos para um grande comício que seria realizado no largo da Matriz, às 16 horas; nele, seria discutido, entre a classe obreira, o advento da parede. O mês era de inverno, mas o frio não impediu que cerca de mil trabalhadores de diversos estabelecimentos comparecessem diante da igreja e ouvissem seu colega, o operário José Freire, falar sobre o difícil dia a dia dele e dos outros camaradas do município, no interior das fábricas. Aos poucos, os homens, mulheres e adolescentes que ali estavam foram se identificando e apoiando o discurso daquela liderança que, junto dos seus, viam que suas vidas cada dia mais se distanciavam da condição material dos seus patrões, levando-os a passar por uma verdadeira crise de subsistência. ${ }^{30}$

A reunião no largo da Matriz não ocorreu exclusivamente por ser a praça um espaço aberto que comportava grande número de pessoas. A ocupação do espaço público, sobretudo em lugares frequentados pela elite, era uma estratégia do movimento operário para chamar a atenção e angariar apoio da população ao movimento paredista, e já havia sido testada em São Paulo, cidade na qual os trabalhadores realizaram comícios em plena praça da Sé. ${ }^{31}$ Outra prática comum do movimento operário durante a Primeira República, e que foi seguida pelos piracicabanos, foi a formação e o desenvolvimento de cortejos. ${ }^{32}$ Após a reunião no largo da Matriz, os trabalhadores em massa caminharam pelas principais ruas do centro do município, pararam em frente às sedes da imprensa e também na casa do juiz de direito da comarca - o senhor Raphael Marques Cantinho - para pedir apoio ao movimento. Terminaram o cortejo retornando ao largo da Matriz, onde decidiram todos pela greve. ${ }^{33}$

Quando escureceu, nesse mesmo dia 16, um grupo de operários se dirigiu ao Engenho Central, que funcionava durante o período noturno, e clamou para que ali os operários cruzassem os braços. Antes mesmo de acontecer o comício no largo da Matriz, na manhã dessa segunda-feira, os trabalhadores do Engenho Monte Alegre já haviam cessado suas atividades e conquistado da gerência um aumento de $10 \%$ nos salários de todos os funcionários. A ação dos montealegrinos motivou todos os demais trabalhadores da cidade e já na tarde desse dia os operários da Fábrica Arethusina e da Casa Krähenbühl não trabalharam. No entanto, aquele primeiro dia de greve já havia sinalizado que a semana seria difícil para a classe obreira, pois naquela mesma noite, na saída do Engenho, houve tensões e brigas, não muito bem explicadas pela imprensa, mas que terminaram com operários exaltados e vidraças quebradas na rua do Rosário. ${ }^{34}$

30 Jornal de Piracicaba, Piracicaba, 17 jul. 1917. Biblioteca Municipal de Piracicaba, Piracicaba, SP.

31 BIONDI; TOLEDO, op. cit.

32 Idem.

33 Jornal de Piracicaba, Piracicaba, 17 jul. 1917. Biblioteca Municipal de Piracicaba, Piracicaba, SP.

34 Jornal de Piracicaba, Piracicaba, 17 jul. 1917. Biblioteca Municipal de Piracicaba, Piracicaba, SP. 
Dia 17 de julho, a cidade de Piracicaba amanhecia com ares completamente diferentes daqueles que a população de quase 67 mil cidadãos estava habituada. ${ }^{35} \mathrm{~A}$ pedido dos grevistas, o comércio local e todas as pequenas indústrias, como fabriquetas de calçados, de arados e de máquinas de beneficiar arroz, fecharam suas portas. ${ }^{36}$ Nesse dia, novo cortejo ocorreu pela cidade com mais de mil trabalhadores e trabalhadoras, e, dessa vez, a parada foi feita na Sociedade Beneficente Operária, fundada em 1905, ${ }^{37}$ onde uma das lideranças do movimento solicitou uma bandeira e Ihe foi entregue a flâmula dessa associação. Empunhando-a ao alto e à frente do cortejo, sob vivas e aclamações, seguiram todos para o salto de Piracicaba, depois para a fábrica de tecidos Arethusina e por último para o bairro Vila Rezende, onde estava localizado o Engenho Central, pedindo de fábrica em fábrica que os patrões assinassem um acordo com toda classe proletária. ${ }^{38}$ Foi formada uma comissão operária, ao modelo do Comitê de Defesa Proletária de São Paulo, com o objetivo de representar os grevistas e dentre seus membros constavam: ${ }^{39}$

João Freidemberg
Antonio Breviato
Guilherme de Gori
João Craveiro
Herculano Monaco
Jorge Sacone
Benedito João de Camargo
Domingos Raphael
Hermínio Guirado

A pauta de reivindicações apresentada pela Comissão Operária de Piracicaba foi idêntica àquela pleiteada em grande parte do território nacional. A classe obreira do interior já contava com a experiência paulistana, e as conquistas na capital serviam como argumento para mudanças na vida dos piracicabanos. As solicitações eram:

- Garantia de que nenhum operário fosse dispensado por ter participado da greve.

- Fim do trabalho de menores de 14 anos nas fábricas e oficinas.

- Que os menores de 18 anos não fossem ocupados com trabalhos noturnos.

- Abolição do trabalho das mulheres nas fábricas.

- Aumento de $20 \%$ dos salários.

- Que o pagamento dos salários fosse efetuado pontualmente nos dias 5 ou 16 do mês.

- Jornada de 8 horas de trabalho.

35 NETTO, Cecílio Elias. Os primeiros dados oficiais de Piracicaba. A Província. Disponível em: http://www. aprovincia.com.br/bom-dia/vila-rezende-nicho-da-alma/. Acesso em: 3 abr. 2020.

36 Jornal de Piracicaba, Piracicaba, 17 jul. 1917. Biblioteca Municipal de Piracicaba, Piracicaba, SP.

37 TERCl, op. cit.

38 Jornal de Piracicaba, Piracicaba, 18 jul. 1917. Biblioteca Municipal de Piracicaba, Piracicaba, SP.

39 Idem. 
- Aumento de $50 \%$ sobre todo o trabalho extraordinário.

- Que fosse garantido aos operários trabalho permanente.

- Que fossem implantadas as feiras livres em Piracicaba.

- Que os operários gozassem das mesmas conquistas dos operários de São Paulo. ${ }^{40}$

A organização dos piracicabanos logo chamou a atenção da polícia e no mesmo dia 17 desembarcaram na estação Sorocabana 26 praças vindos de São Paulo; o secretário de justiça da capital ofereceu ainda mais reforços para contenção da greve em Piracicaba. Exatamente às 15 horas, o delegado fez circular um boletim no qual exigia que os trabalhadores não se aglomerassem sob ameaça do uso da força e, nessa mesma tarde, houve confronto entre os manifestantes e os policiais que efetuaram a prisão de um operário. A repressão não esmoreceu os proletários que conquistaram depois disso o apoio dos chauffeurs e dos cocheiros; os bondes do município também foram completamente paralisados. O gerente do Engenho Central sinalizou trégua e disse que poderia atender aos pedidos da Comissão Proletária aumentando em $20 \%$ o salário dos empregados, mas o movimento paredista prosseguiu com os trabalhadores se dirigindo ao Engenho Monte Alegre a fim de requerer o mesmo aumento. Foi marcada nova reunião para o dia seguinte no largo da Matriz. ${ }^{41}$

No terceiro dia de paralisação, 18 de julho, a greve assumia as mesmas proporções do dia anterior, o comércio mantinha-se fechado, os bondes circularam, mas não se viu carroças ou outros veículos nas ruas, e os operários dos grandes e pequenos estabelecimentos piracicabanos continuavam com as mãos fechadas e braços empunhados ao alto. Da janela do Hotel Central, lideranças, como Benedito João de Camargo, clamavam união dos companheiros até que todos fossem contemplados em sua pauta comum. Houve novo cortejo e às 10 horas da manhã os trabalhadores se dirigiram ao Engenho Monte Alegre onde houve novos confrontos entre os grevistas e os agentes da polícia, mas os operários conquistaram o aumento pretendido e o compromisso do estabelecimento com alguns pontos da pauta apresentados pela comissão proletária. À tarde, a imprensa foi chamada a intervir com o objetivo de ajudar a selar o acordo no Engenho Central, o que de fato ocorreu. ${ }^{42}$

Paulatinamente os patrões das grandes fábricas e pequenas oficinas assinaram um compromisso de aumentar os salários dos trabalhadores. Quando as gerências do Engenho Monte Alegre e do Engenho Central aceitaram o aumento de $20 \%$ nos salários e jornada de 8 horas de trabalho, o clima da greve começou a mudar caminhando para seu encerramento. À noite, os operários acataram o fim do movimento paredista e o retorno ao trabalho na manhã seguinte. Porém, antes da decretação do término da parede, os trabalhadores foram até o

40 Ibidem. Grifos da autora.

41 Ibidem.

42 Jornal de Piracicaba, Piracicaba, 19 jul. 1917. Biblioteca Municipal de Piracicaba, Piracicaba, SP. 
presídio da cidade acompanhar a soltura do companheiro preso durante um dos embates com a polícia, o que também havia deixado alguns operários feridos no dia anterior. ${ }^{43}$

$\mathrm{Na}$ aurora do dia 19, aquela gente humilde que havia se organizado com o objetivo de conquistar mudanças sociais que melhorassem ou mesmo transformassem radicalmente as condições de vida da classe trabalhadora do país, se encontrava nos seus postos de trabalho. Dia 20, a cidade amanhecia em perfeita normalidade. Diversos industriais acataram naquele momento o aumento de $20 \%$ dos salários e a jornada de 8 horas de trabalho, o que fez com que a greve fosse considerada vitoriosa pelo movimento proletário piracicabano. Houve comemorações no largo da Matriz com a presença de três bandas operárias e ouviramse vivas calorosos dos trabalhadores ao som do hino operário. Foi feito ainda um último cortejo em agradecimento à imprensa. Dessa greve resultou a fundação da Liga Operária de Piracicaba, cujo objetivo era lutar pela manutenção dos direitos conquistados e por melhores condições de trabalho. ${ }^{44} \mathrm{~A}$ primeira diretoria foi empossada no dia 7 de agosto, após uma reunião realizada na rua Moraes Barros, 69. Compuseram a direção da liga os operários: ${ }^{45}$

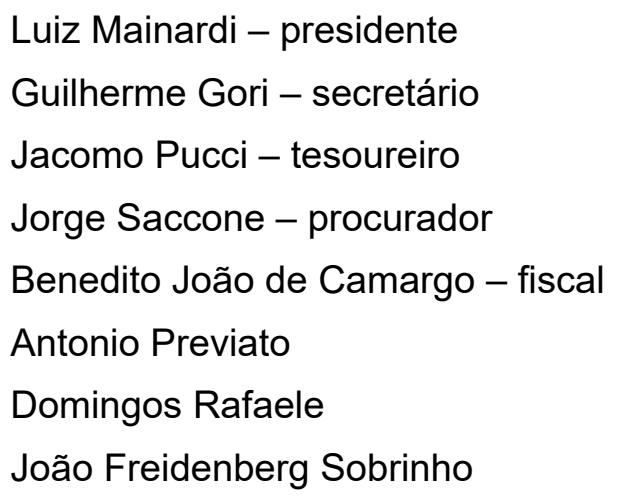

Todavia, os meses e anos seguintes demonstrariam que a batalha do movimento operário no interior, e em todo o país, por uma condição de vida digna, estava apenas no início. Como aconteceu em várias regiões Brasil, muitos empresários piracicabanos que se comprometeram com as reivindicações da classe proletária na grande greve geral de 1917 não cumpriram os acordos após o término do movimento paredista. ${ }^{46} \mathrm{Em} 1919$, os operários ainda lutavam pela jornada de 8 horas de trabalho para todas as categorias. Vale lembrar que, nessa época, esses homens e mulheres permaneciam 14 horas dentro de um estabelecimento fabril sem direito aos finais de semana e podendo cumprir até mesmo 16 horas diárias em momentos de crise econômica ou política, como de fato ocorreu durante a Primeira Guerra Mundial (19141918). ${ }^{47}$

43 Idem.

44 Jornal de Piracicaba, Piracicaba, 20 jul. 1917. Biblioteca Municipal de Piracicaba, Piracicaba, SP.

45 Jornal de Piracicaba, Piracicaba, 7 ago. 1917. Biblioteca Municipal de Piracicaba, Piracicaba, SP.

46 BIONDI; TOLEDO, op. cit

47 Sobre a classe operária durante a Primeira República, ver: BATALHA, Claudio. O movimento operário na Primeira República. Rio de Janeiro: Jorge Zahar Editora, 2000. Sobre a greve de 1917, ver também: FRACCARO, Glaucia. O direito das mulheres, feminismo e trabalho no Brasil (1917-1937). Rio de Janeiro: FGV, 2019. 
A GREVE GERAL DE 1919 teve ares bastante distintos daqueles verificados no município durante a greve dois anos antes. Quando, no início do mês de maio, os operários começaram a distribuir panfletos pela cidade projetando a possibilidade de uma nova paralisação, a polícia logo interveio e fez circular um boletim proibindo as reuniões operárias em praça pública, sob ameaça do uso da força. ${ }^{48}$ Todavia, o medo não foi maior que o desejo de mudança e, no dia 17 de maio, trabalhadores do Engenho Central, da Fábrica Arethusina e da Casa Krähenbühl decidiram não trabalhar até que melhores condições de trabalho fossem impostas às fábricas. Ainda não era uma greve geral, apenas algumas categorias decidiram lutar por melhores salários e ao longo daquele primeiro semestre negociações se arrastaram entre patrões e empregados. ${ }^{49}$

Primeiro foi a fábrica de tecidos que aceitou a reivindicação de aumento de $15 \%$ no pagamento do seu pessoal. ${ }^{50}$ Quase uma semana depois, os trabalhadores do Engenho Central conquistaram um aumento nos seus ordenados. ${ }^{51}$ Nada foi relatado na imprensa sobre os demais estabelecimentos, mas aparentemente todas as indústrias da cidade funcionavam normalmente no advento do sexto mês do ano. A calmaria, no entanto, não durou muito tempo. Isso porque, em julho, os trabalhadores da Estrada de Ferro Sorocabana decidiram cruzar os braços na capital paulista e logo as notícias da paralisação não apenas chegaram em Piracicaba como também os ferroviários do município se insuflaram contra suas precárias condições de trabalho. ${ }^{52}$

No segundo dia do mês de julho, maquinistas, foguistas, telegrafistas e outros empregados abandonaram seus postos de trabalho na estação da Sorocabana em Piracicaba. ${ }^{53}$ Os grevistas pediam $30 \%$ de aumento salarial e a jornada de 8 horas de trabalho diário. A essa altura, a Liga Operária de Piracicaba já possuía uma sede social, localizada na rua Prudente de Moraes, na qual os ferroviários piracicabanos passaram a se reunir. ${ }^{54} \mathrm{O}$ clima na cidade começou a ficar ainda mais tenso quando, no dia 4 de julho, foram arrancados trilhos no quilômetro 232. Foi nesse dia que os operários de todos os estabelecimentos industriais do município decidiram se solidarizar com os camaradas da Estrada de Ferro, declarando a parede geral; e também com o objetivo de lutar mais uma vez pela redução das exaustivas horas de trabalho e por $25 \%$ de aumento no ordenado para aqueles que não haviam obtido adição na greve de maio. ${ }^{55}$

A situação na região era calamitosa para a elite piracicabana que estava habituada a viajar e a ver sua produção escoada para as demais regiões do estado. No início daquele mês

48 Jornal de Piracicaba, Piracicaba, 13 maio 1919. Biblioteca Municipal de Piracicaba, Piracicaba, SP.

49 Jornal de Piracicaba, Piracicaba, 17 maio 1919. Biblioteca Municipal de Piracicaba, Piracicaba, SP.

50 Jornal de Piracicaba, Piracicaba, 25 maio 1919. Biblioteca Municipal de Piracicaba, Piracicaba, SP.

51 Jornal de Piracicaba, Piracicaba, 1 jun. 1919. Biblioteca Municipal de Piracicaba, Piracicaba, SP.

52 Jornal de Piracicaba, Piracicaba, 2 jul. 1919. Biblioteca Municipal de Piracicaba, Piracicaba, SP.

53 Idem.

54 Jornal de Piracicaba, Piracicaba, 4 jul. 1919. Biblioteca Municipal de Piracicaba, Piracicaba, SP.

55 Jornal de Piracicaba, Piracicaba, 5 jul. 1919. Biblioteca Municipal de Piracicaba, Piracicaba, SP. 
de julho, os trens da capital não partiram e o percurso de Piracicaba até Jundiaí também estava interditado. ${ }^{56} \mathrm{~A}$ imprensa e a polícia passaram a atuar em franca comunhão, e logo tomaram as páginas do jornal as atuações e os avisos do delegado da cidade - o senhor Djalma Goulart - de repressão ao movimento paredista. ${ }^{57}$ Dia 5, os estabelecimentos amanheceram fechados e alguns dos poucos comerciantes que se arriscaram a abrir acabaram por fechar as portas mais cedo, pois a cidade se encontrava em clima de greve geral. ${ }^{58}$

Ao cair da noite do quinto dia do mês de julho, um grupo de operários se dirigiu à empresa Bragantina e cortou os fios telefônicos responsáveis por fazer a comunicação de Piracicaba com São Paulo e também com outras pequenas cidades ao redor do município. O objetivo era claramente evitar que chegassem reforços para a polícia municipal que já vinha, por meio de boletins, ameaçando usar a violência para conter a greve. A ação do grupo desencadeou grande onda de repressão e naquela mesma madrugada foram efetuadas prisões de alguns líderes operários. ${ }^{59} \mathrm{~A}$ partir desse momento, começou uma verdadeira "caça às bruxas" na imprensa piracicabana. Dia a dia foram publicadas matérias sobre o inquérito policial aberto contra trabalhadores da Liga Operária que vinham organizando o movimento paredista. ${ }^{60}$

Após a prisão de alguns acusados, operários se reuniram em frente à cadeia municipal, a fim de exigir a liberdade dos companheiros. ${ }^{61} \mathrm{O}$ Jornal de Piracicaba, no entanto, defendeu a necessidade da punição, afirmando ter havido entre os operários presos a intenção de saquear o comércio local. Para a imprensa e para o delegado, haveria uma articulação das lideranças grevistas no sentido de evitar que polícia obtivesse reforços, objetivando assaltar os estabelecimentos do município. A paralisação de centenas de trabalhadores pela jornada de 8 horas diárias cedeu espaço no grande jornal local para aquilo que os jornalistas chamaram de "Plano Bolchevista". ${ }^{62}$ Alguns dos diretores da Liga Operária foram explicitamente perseguidos e dentre as acusações constavam: anarquismo, bolchevismo e maximalismo. ${ }^{63}$

De um lado, a Liga Operária de Piracicaba pedia para que os operários permanecessem unidos e não comparecessem ao trabalho; do outro, a imprensa fazia um apelo para que os trabalhadores não se deixassem levar por "agitadores anarquistas". ${ }^{64} \mathrm{O}$ fato é que, após o acontecimento na Bragantina, a mobilização grevista foi completamente desarticulada, ainda que, ao final, os trabalhadores tenham obtido algumas vitórias. Após dez dias de paralisação ininterrupta dos trens, a Companhia Sorocabana de Estrada de Ferro decide atender às reivindicações dos seus trabalhadores e concede aumento salarial de $25 \%$ e a jornada de 8 horas de trabalho. ${ }^{65} \mathrm{~A}$ fábrica de tecidos Arethusina também se comprometeu com o aumento

56 Jornal de Piracicaba, Piracicaba, 1 jul. 1919. Biblioteca Municipal de Piracicaba, Piracicaba, SP. 57 Jornal de Piracicaba, Piracicaba, 9 jul. 1919. Biblioteca Municipal de Piracicaba, Piracicaba, SP. 58 Idem.

59 Ibidem

60 Jornal de Piracicaba, Piracicaba, 11 jul. 1919. Biblioteca Municipal de Piracicaba, Piracicaba, SP.

61 Jornal de Piracicaba, Piracicaba, 9 jul. 1919. Biblioteca Municipal de Piracicaba, Piracicaba, SP.

62 Jornal de Piracicaba, Piracicaba, 12 jul. 1919. Biblioteca Municipal de Piracicaba, Piracicaba, SP.

63 Jornal de Piracicaba, Piracicaba, 17 jul. 1919. Biblioteca Municipal de Piracicaba, Piracicaba, SP.

64 Jornal de Piracicaba, Piracicaba, 11 jul. 1919. Biblioteca Municipal de Piracicaba, Piracicaba, SP.

65 Jornal de Piracicaba, Piracicaba, 10 jul. 1919. Biblioteca Municipal de Piracicaba, Piracicaba, SP. 
do ordenado e a redução da carga horária de labor, mas pouco ou nada foi escrito na imprensa local sobre os outros estabelecimentos que no dia 10 de julho funcionavam normalmente. ${ }^{66}$

O término do movimento paredista em 1919 não significou, no entanto, o fim das perseguições às lideranças grevistas em Piracicaba. Após a greve, durante dias, a imprensa estampou nomes dos acusados de terem participado do ato na Bragantina. Os operários Ângelo Bragaia, Paulo Antônio e João Felício ficaram marcados nas páginas dos jornais como delatores ${ }^{67}$ e Mario Passini foi acusado de ser o cabeça do plano. O periódico qualificou Mario Passini como o "terrível secretário da Liga Operária" ${ }^{88}$ e o inquérito policial aberto contra ele, assim como recortes do jornal $A$ Tarde, aparentemente o único que se posicionou ao lado dos trabalhadores naquele evento, ainda podem ser consultados em um arquivo da cidade. ${ }^{69}$

\section{Algumas considerações sobre as greves no município e suas conexões com São Paulo}

As GReVes Gerais EM PIRACICABA mantiveram conexões não apenas com São Paulo, mas com uma conjuntura histórica nacional e internacional. No ano de 1917, trabalhadores de diferentes países sofriam as consequências da Primeira Guerra Mundial (1914-1918). Os países latino-americanos não participaram diretamente desse conflito bélico, mas nem por isso passaram ilesos ao confronto. Por um lado, a indústria brasileira foi incentivada a produzir muitos dos artigos que antes da guerra eram importados da Europa ou dos Estados Unidos, uma vez que essas regiões estavam agora concentradas em abastecer seus exércitos; por outro lado, aquilo que não podia ser produzido no Brasil e precisava ser adquirido de fora, entrava no país com um valor muito mais alto. ${ }^{70}$ Os salários dos operários brasileiros não acompanhavam a alta no preço das mercadorias, principalmente dos alimentos, e com as fábricas produzindo a todo o vapor para compensar as importações, a jornada de trabalho, já longa para aqueles homens e mulheres, se ampliou fortemente. ${ }^{71}$

No mês de abril de 1917, os Estados Unidos da América ingressaram na guerra e essa nação era uma das principais fornecedoras de grãos para o Brasil. A alta nos preços dos alimentos em todo o território brasileiro foi quase imediata e sentida no bolso de todos os operários do país, incluindo os piracicabanos. ${ }^{72}$ Não foi sem motivo, portanto, que na grande greve geral de 1917, os trabalhadores do município encamparam a luta pela implantação das feiras livres em Piracicaba, enviando à Câmara Municipal um grupo de operários representantes para tratar especificamente desse assunto. Na capital paulista, as feiras livres

66 Jornal de Piracicaba, Piracicaba, 11 jul. 1919. Biblioteca Municipal de Piracicaba, Piracicaba, SP.

67 Jornal de Piracicaba, Piracicaba, 16 jul. 1919. Biblioteca Municipal de Piracicaba, Piracicaba, SP.

68 Jornal de Piracicaba, Piracicaba, 13 jul. 1919. Biblioteca Municipal de Piracicaba, Piracicaba, SP.

69 Ver: Processo-crime de Mario Passini no Acervo Judiciário do Centro Cultural Martha Watts, em Piracicaba, SP.

70 DEAN, Warren. A industrialização de São Paulo. 1880-1945. Rio de Janeiro/São Paulo: Difel, 1971. p. 94-114.

71 PINHEIRO, Paulo Sérgio, O proletariado industrial na Primeira República. In: FAUSTO, Boris (org). História geral da civilização brasileira, t. III, v. 2, Rio de Janeiro/São Paulo: Difel, 1978.

72

DEAN, op. cit. 
já haviam sido adotadas pela prefeitura desde 1914 e para a classe trabalhadora representava a possibilidade de comprar produtos a um preço mais barato, livres dos impostos do mercado municipal que em Piracicaba era o principal espaço de compras desde o ano $1888 .{ }^{73}$

Além da Primeira Guerra Mundial, o ano 1917 foi marcado pelo advento da Revolução Russa e por uma série de grandes greves operárias na Alemanha, França, Grã-Bretanha, Itália, Áustria e na Espanha. ${ }^{74}$ A própria Revolução Bolchevique foi um evento ligado a um processo de organização sindical e política da classe obreira. O historiador Eric Hobsbawm apontou que a revolução de fevereiro de 1917 na Rússia teve início quando uma manifestação de operárias coincidiu com o fechamento das fábricas metalúrgicas pelos proprietários, o que resultou em uma greve geral, com a ocupação de São Petersburgo por centenas de trabalhadores. ${ }^{75}$ As mobilizações operárias do ano de 1917 em todo o mundo ecoaram muito além dessa data e ainda estavam vivas na memória da elite e da classe proletária no ano da greve geral de 1919 no Brasil.

O corte nos fios telefônicos em Piracicaba por parte de alguns operários foi chamado por um dos principais jornais da cidade em 1919 de "Plano Bolchevista" e, para os jornalistas, o ato na empresa Bragantina seria o resultado da presença, no interior do movimento operário piracicabano, de elementos maximalistas que eram aqueles socialistas que olhavam para a revolução que ocorreu na Rússia em novembro de 1917 como inspiradora de sua ação política. ${ }^{76} \mathrm{O}$ mesmo evento também foi compreendido à luz das greves operárias europeias e, de acordo com o Jornal de Piracicaba, o plano que objetivava saquear a cidade era uma imitação do movimento anarquista que vinha ocorrendo em alguns capoluogos italianos. ${ }^{77}$

A imagem caricata do perigoso italiano anarquista extrapolou o período da Primeira República e até hoje está presente em romances, filmes e documentários. ${ }^{78} \mathrm{~A}$ historiografia do trabalho no entanto vem demonstrando, desde pelo menos a década de 1990, a multiplicidade étnica e a complexidade ideológica do movimento organizado da classe proletária, desconstruindo seus estereótipos. ${ }^{79}$ A referência à Revolução Russa e a alusão à Itália, tudo sempre tratado como sinônimo de subversão e desordem, não era uma originalidade da imprensa piracicabana; em todo o país essas narrativas foram utilizadas com o objetivo de desqualificar o movimento organizado da classe obreira pelos seus direitos trabalhistas e civis. ${ }^{80}$

Além das conexões com o cenário internacional, o movimento grevista de Piracicaba manteve uma pauta de reivindicações idêntica àquela pleiteada em todo o território brasileiro.

73 Jornal de Piracicaba, Piracicaba, 18 jul. 1917. Biblioteca Municipal de Piracicaba, Piracicaba, SP.

74 BIONDI; TOLEDO, op. cit., p. 95.

75 HOBSBAWM, Eric, Era dos extremos. O breve século XX, 1914-1991. São Paulo: Companhia das Letras, 1995. p. 66-71.

76 Jornal de Piracicaba, Piracicaba, 12 jul. 1919. Biblioteca Municipal de Piracicaba, Piracicaba, SP.

77 Jornal de Piracicaba, Piracicaba, 23 jul. 1919. Biblioteca Municipal de Piracicaba, Piracicaba, SP.

78 BATALHA, op. cit.

79 Ver: TOLEDO, Edilene T. Travessias revolucionárias - ideias de militantes sindicalistas em São Paulo e na Itália (1890-1940). Campinas: Unicamp, 2004.

80 Ver: BIONDI, Luigi. Classe e nação: trabalhadores e socialistas Italianos em São Paulo. Campinas: UNICAMP, 2011. 
No Brasil, na deflagração da greve geral de 1917, os trabalhadores não tinham folga semanal garantida por lei e, em geral, descansavam apenas no domingo, ou nem mesmo no domingo, dia reivindicado pela Igreja Católica. Também tinham longas jornadas de trabalho, sem férias. Era comum o atraso no pagamento, pois não havia nenhuma legislação que exigisse do empregador o pagamento pontual dos ordenados. O trabalho dos menores de dez anos nas fábricas, geralmente filhos dos operários, era rotineiro e está documentado nas inúmeras fontes iconográficas do período. A desigualdade salarial entre homens e mulheres, que eram submetidos às mesmas condições de exploração, com a adição do assédio sexual para as operárias, também era uma realidade. O pagamento pontual dos salários, a redução da jornada de trabalho, a regularização do trabalho feminino, a abolição do trabalho infantil e o aumento salarial, dada a grande carestia de vida - todos pontos defendidos pela Comissão Operária de Piracicaba em 1917 -, foram reivindicações da classe obreira no Rio de Janeiro, em Porto Alegre, no Recife e em muitas outras pequenas e grandes cidades em 1917 e 1919. ${ }^{81}$ Todavia, o vínculo do movimento operário piracicabano com São Paulo foi ainda mais estreito.

A greve geral de 1917 estimulou na capital a organização de muitos sindicatos, na época também chamados de ligas ou uniões. A própria Federação Operária de São Paulo (FOSP) havia sido fundada em novembro de 1905, mas, dadas inúmeras dificuldades, desaparece em 1912, e ressurge como um dos resultados do movimento paredista de 1917. A FOSP foi uma organização criada a partir da iniciativa do sindicato dos carpinteiros, chamados trabalhadores da madeira, e sua sede estava localizada na região da Sé, em São Paulo. A entidade atendia principalmente os operários das fábricas na zona leste e se baseava sobretudo nas ligas operárias da capital, mas também foi a responsável por ajudar a organizar vários novos sindicatos no interior. ${ }^{82} \mathrm{~A}$ Liga Operária de Piracicaba, como a FOSP, também foi criada imediatamente após o término da greve de 1917, e por meio da imprensa piracicabana é possível acompanhar o passo a passo da sua fundação. Em uma matéria da Gazeta de Piracicaba, no dia 25 de julho, foi noticiado que os operários do município solicitaram o estatuto do Centro Operário de São Paulo a fim de criarem, a partir deste, o seu próprio regulamento. ${ }^{83}$ Após algum tempo, a Liga Operária de Piracicaba também se filiou à FOSP. ${ }^{84}$

Outro aspecto que une o interior à capital se refere ao papel desempenhado pelas Sociedades de Mútuo Socorro, algumas delas de características étnicas, isso em um momento no qual o estado paulista tinha sofrido os impactos da chegada das grandes levas de imigrantes europeus. A composição étnica da classe trabalhadora em Piracicaba não diferia daquela encontrada em São Paulo nas duas primeiras décadas do século XX. ${ }^{85}$ Havia um significativo número de italianos, espanhóis e portugueses no município, o que explica

81 CASTELLUCCI, op. cit.

82 BIONDI; TOLEDO, op. cit.

83 Gazeta de Piracicaba, Piracicaba, 25 jul. 1917. Biblioteca Municipal de Piracicaba, Piracicaba, SP.

84 A Plebe, São Paulo, 8 set. 1917. Arquivo Edgard Leuenroth /AEL, Unicamp, Campinas, SP.

85 HALL, Michael. A imigração na cidade de São Paulo. In: PORTA, Paula (org.). História da cidade de São Paulo. A cidade na primeira metade do século XX, 1890-1954. Rio de Janeiro: Paz e Terra, 2005, v. 3. 
a fundação, em 1887, da Società Italiana di Mutuo Soccorso de Piracicaba, da Sociedade Beneficente Espanhola de Piracicaba, em 1898, e da Beneficência Portuguesa, em 1904. ${ }^{86} \mathrm{As}$ sociedades de mútuo socorro desempenharam um papel importante no interior do movimento operário em São Paulo e também em Piracicaba. Na capital, ajudaram a representar muitos operários das categorias que ainda não contavam com um sindicato, extrapolando a função assistencialista como, por exemplo, na ajuda funerária aos sócios, e se empenhando na luta por direitos no mundo do trabalho. ${ }^{87}$ Em Piracicaba, a Sociedade Beneficente Operária era a principal organização proletária até 1917, e foi a sua bandeira que os trabalhadores levantaram em seus cortejos pelo centro do município durante o movimento paredista. ${ }^{88}$

Existe um aspecto que enlaça mais uma vez os movimentos paredistas de São Paulo e Piracicaba em 1917, mas que também manteve singularidades nas duas cidades: o papel desempenhado pela imprensa durante a greve. Foi formado, na capital, um comitê de imprensa, com o objetivo de intermediar o conflito entre os empresários paulistanos e o Comitê de Defesa Proletária. A comissão da imprensa, liderada por Nereu Rangel Pestana - diretor do jornal $O$ Combate - e Umberto Serpieri - do jornal Fanfulla -, foi motivada tanto pelo alastramento da greve que tomava a cidade e vinha ganhando ares de uma verdadeira revolta urbana, quanto pelo entendimento, por parte de alguns jornalistas, da necessidade de uma conciliação frente à situação desesperadora dos trabalhadores naquela época. ${ }^{89} \mathrm{Em}$ um momento em que a imprensa operária na capital havia sido silenciada pela repressão policial, jornais de maior público, como o Fanfulla, foram um ponto de referência importante para difusão das atividades de organização e protestos que vinham sendo desenvolvidas pelos trabalhadores. Grande parte dos dirigentes dos periódicos operários atuaram como lideranças do movimento grevista - dentre eles podemos citar o tipógrafo anarquista Edgard Leuenroth diretor do jornal A Plebe - e, em alguns casos, o conflito os afastou temporariamente da confecção dos impressos. Após o término da parede, os jornais operários puderam se reorganizar e voltaram a circular, ainda que sempre sob vigilância dos órgãos de repressão do governo. ${ }^{90}$

$\mathrm{Na}$ cidade de Piracicaba, a imprensa também foi convocada a intermediar alguns dos conflitos travados entre os operários e seus patrões. No dia 18 de julho, a comissão operária se dirigiu até a sede do Jornal de Piracicaba e lá os trabalhadores solicitaram ao redator do jornal, Pedro Krähenbühl, que ele fosse até o Engenho Central conversar com o diretor-gerente, o senhor Dr. Kock, sobre o aumento dos ordenados, na intenção de ajudar os empregados daquele estabelecimento, o que de fato ocorreu. O jornal, durante o movimento paredista de 1917, insistiu na justiça das reivindicações dos trabalhadores, o que lhe rendeu agradecimentos por parte dos operários ao fim da parede. ${ }^{91}$

86 GUERRINI, op. cit.

87 BATALHA, op. cit.

88 Jornal de Piracicaba, Piracicaba, 18 jul. 1917. Biblioteca Municipal de Piracicaba, Piracicaba, SP.

89 BIONDI; TOLEDO, op. cit., p. 63.

90 Idem.

91 Jornal de Piracicaba, Piracicaba, 19 jul. 1917. Biblioteca Municipal de Piracicaba, Piracicaba, SP. 
Pedro Krähenbühl era neto do fundador da Casa Krähenbühl. ${ }^{92} \mathrm{O}$ Jornal de Piracicaba, fundado em 1900 e ativo até hoje, foi um periódico que manteve ao longo da sua trajetória um vínculo estreito com a elite da cidade. O apoio dado pelo jornalista ao movimento da classe obreira em 1917 foi um dos momentos de exceção na história desse periódico e pode estar relacionado ao fato de, em São Paulo, a grande imprensa ter assumido esse papel de intermediadora, com resultados que contribuíram para o fim do conflito. Contudo, muito mais comum foi o posicionamento apresentado pelo jornal em 1919, quando o movimento grevista foi duramente criticado pelo órgão de comunicação e houve uma intensa campanha contra os dirigentes da Liga Operária. Apesar disso, em Piracicaba, as lideranças operárias souberam se utilizar das brechas deixadas pela grande imprensa e fizeram dela um espaço de comunicação com as bases.

A falta de jornais operários na cidade, que só aparecem de forma significativa a partir da segunda metade do século $\mathrm{XX}$, levou os dirigentes operários a se comunicarem com os trabalhadores através do Jornal de Piracicaba (1900) e da Gazeta de Piracicaba (1882). Foi comum, portanto, que as reuniões, assembleias e festas da Liga Operária fossem informadas nesses periódicos. ${ }^{93}$ Houve também uma importante atuação de alguns militantes operários socialistas e anarquistas nos grandes jornais do município. Em 1904, a Gazeta de Piracicaba noticiou a terceira conferência promovida pelo Grupo S. Anárquico Germinal em Piracicaba, e nesse ano o Partido Socialista de Piracicaba promoveu a festa do dia $1^{\circ}$ de maio, o que aponta para a presença de militantes socialistas e anarquistas na cidade desde, pelo menos, essa época ${ }^{94}$ Alguns desses militantes se tornaram verdadeiras pontes de ideias do movimento operário de Piracicaba com São Paulo e o mundo; esse foi o caso do italiano Vittorio Buttis.

Buttis nasceu em Veneza, em 24 de julho de 1866, e antes de emigrar para o Brasil, em 1911, passou pela Suíça e pela Alemanha. Foi no seu país de origem que se tornou um socialista, conhecendo as lutas operárias e camponesas através da leitura de jornais. Em São Paulo, dirigiu o jornal Avanti!, o principal jornal socialista durante a Primeira República, por cinco números. Depois de um tempo na capital, Vittorio Buttis se dirigiu a Piracicaba para trabalhar na fábrica de máquinas de costura Singer. Nesse período, a embaixada italiana no Rio de Janeiro recebeu a notícia da presença dele no país, com a observação de que devia ser mantido sob controle como indivíduo perigoso. No município, atuou como jornalista, escrevendo matérias em língua italiana para o jornal O Popular e para o Jornal de Piracicaba. Nesses dois periódicos, Buttis expôs suas ideias políticas de socialista e incitou o movimento operário local, propondo um programa de política social e de educação das massas camponesas e operárias. Em um artigo publicado em 1913, no Jornal de Piracicaba, denominado "II nostro augurio", Buttis lamentou o desperdício de recursos e esforços de

92 MARTINS, Carlos Roberto Sodero; NETTO, Samuel Pfromm. Pena, escudo e lança: cem anos do Jornal de Piracicaba. Piracicaba: Editora Forpap, 2000.

93 Jornal de Piracicaba, Piracicaba, 30 ago. 1917. Biblioteca Municipal de Piracicaba, Piracicaba, SP.

94 TERCI, op. cit. 
italianos cultos no Brasil em jornais e instituições que não tinham conseguido atingir a grande massa dos imigrantes italianos: os trabalhadores das fazendas. Buttis vivia nesse momento em meio aos canaviais piracicabanos e muitos dos trabalhadores rurais nessa cidade também eram seus compatriotas, o que provavelmente contribuiu para sua preocupação com a organização dos trabalhadores no campo. Após dois anos e meio no Brasil, escreveu para a Federazione Socialista Italiana nos Estados Unidos, com o auxílio de amigos, e foi convidado a ir para os EUA ${ }^{95} \mathrm{Em}$ Chicago, ele escreveu suas memórias, publicadas posteriormente em um livro.

Vittorio Buttis foi um militante que passou por Piracicaba e soube utilizar um espaço na grande imprensa para defender seus ideais socialistas, deixando uma contribuição importante para o movimento operário da cidade. ${ }^{96}$ Entretanto, se São Paulo foi uma fonte de inspiração para as organizações obreiras piracicabanas, havendo entre a capital e o município uma grande circulação de ideias e pessoas, por outro, a metrópole, para os trabalhadores piracicabanos, também foi sinônimo de repressão. A greve de 1917 foi uma experiência singular para o movimento operário da cidade; embora contassem com certo apoio da imprensa, os operários das fábricas e os colonos dos engenhos, que formavam o núcleo duro da greve em Piracicaba, sofreram literalmente na pele com a ação policial que vinha da capital. Em 1919, os dirigentes da Liga Operária sabiam que viriam praças da capital para reprimir o movimento paredista que começou no início do ano sob ameaças da polícia. O corte nas linhas telefônicas foi uma tentativa dos trabalhadores de romper a comunicação da polícia com a delegacia de São Paulo, conseguindo assim prosseguir com as reivindicações da classe obreira do município.

Próximos ou distantes da capital, sem dúvida, podemos afirmar que os eventos grevistas de 1917 e 1919 são partes germinantes do movimento operário piracicabano e deixaram marcas indeléveis na história da classe trabalhadora da cidade. Em 1945, foi fundada a primeira Associação dos Trabalhadores Metalúrgicos de Piracicaba. A ata de fundação dessa organização e as fichas preservadas dos primeiros sócios nos permitem observar que, frente a uma grande expansão das indústrias Dedini, não foram apenas os trabalhadores desse estabelecimento que participaram da criação da entidade, mas muitos operários do Engenho de Açúcar Monte Alegre foram protagonistas desse processo, como Silvio Magossi, ajudante de mecânico, nascido em 1902; Tiaravuto Modulo, ajustador mecânico, nascido em 1901; Antonio Ercolino, soldador, nascido em 1899; João Arousom, ajustador mecânico, nascido em

95 Informações sobre Vittorio Buttis podem ser encontradas em TOLEDO, Edilene T. Travessias revolucionárias - ideias de militantes sindicalistas em São Paulo e na Itália (1890-1940). Campinas: Unicamp, 2004, cap. 3, nota de rodapé 39. Há informações sobre Vittorio Buttis no Archivo Centrale dello Stato, Roma (ACRS), acervo do Ministero Degli Interni, Direzione Generale di Pubblica Sicurezza, Casellario Politico Centrale (SPC); consultar pasta 915. Ver também o livro de memórias de Vittorio Buttis: BUTTIS, Vittorio. Memorie di vita di tempesre sociali. Roma: Ediess, 2006.

96 Outro importante militante que passou por Piracicaba foi Alcibiade Bertolotti. Para a polícia italiana, ele era adepto do anarquismo e do sindicalismo revolucionário e, de acordo com a historiadora Edilene Toledo Bertolotti, foi um defensor das ideias socialistas e era um antifascista. Em Piracicaba, por volta do ano 1926, trabalhou na Usina Monte Alegre. Sobre Bertolotti, ver: TOLEDO, op. cit., cap. 2, nota de rodapé 43. Há informações sobre Alcibiade Bertolotti no Archivo Centrale dello Stato, Roma (ACRS), acervo do Ministero Degli Interni, Direzione Generale di Pubblica Sicurezza, Casellario Politico Centrale (SPC); consultar pasta 577. 
1892; Ernesto João Tonin, caldeireiro, nascido em 1901; Wilson Modesto, mecânico, nascido em 1925; Benedito Tonin, mecânico, nascido em 1923; e Natali de Castro, ajustador mecânico, nascido em 1920.97 É difícil afirmar que os trabalhadores montealegrinos que ajudaram a fundar a associação dos metalúrgicos participaram das greves gerais de 1917 e 1919, mas a data de nascimento e a naturalidade piracicabana nos permite vislumbrar que alguns deles experienciaram esses eventos de perto.

No ano de 1947, essa associação foi transformada em sindicato, ativo até hoje, está localizado na rua Prudente de Moraes, 914, no centro de Piracicaba. A origem dessa organização sindical não se deve exclusivamente aos trabalhadores do engenho. Participaram da sua criação operários das empresas Dedini (1920) da fábrica Morlet (1940) e da oficina Santa Cruz (1938), mas certamente os trabalhadores do Engenho Monte Alegre, espaço de luta nas primeiras décadas do século XX, fizeram parte do processo de autoconstituição do movimento operário metalúrgico piracicabano. ${ }^{98}$ No contexto do Brasil da Primeira República ou após a Segunda Guerra Mundial, a luta de cada um desses homens foi também um esforço de transformação de toda uma sociedade, porque muitas vezes, como nas greves gerais de 1917 e 1919, as lutas não se resumiam a melhorar os salários e a reduzir a jornada de trabalho, mas de assegurar a própria existência. Seja na organização de uma parede no início do século ou de um sindicato em 1947, essas são histórias de trabalhadores que, nas pequenas e grandes cidades, procuraram construir um projeto de um país mais justo e mais humano, movidos pela crença na possibilidade efetiva de fazê-lo.

Recebido em: 25/05/2020

Aprovado em: 15/06/2020

97 Ver: Ata da fundação e fichas dos primeiros sócios da Associação dos Metalúrgicos de Piracicaba - Arquivo Histórico do Sindicato dos Trabalhadores Metalúrgicos de Piracicaba - Piracicaba - SP.

98 Idem. 